\title{
Ignisphaera aggregans gen. nov., sp. nov., a novel hyperthermophilic crenarchaeote isolated from hot springs in Rotorua and Tokaanu, New Zealand
}

Correspondence Thomas D. Niederberger tdn@waikato.ac.nz

\author{
Thomas D. Niederberger, ${ }^{1}$ Dorothee K. Götz, ${ }^{1} \dagger$ Ian R. McDonald, ${ }^{2}$ \\ Ron S. Ronimus ${ }^{1}$ and Hugh W. Morgan ${ }^{1}$
Thermophile Research Unit ${ }^{1}$ and Department of Biological Sciences ${ }^{2}$, University of Waikato, Private Bag 3105, Hamilton, New Zealand

\begin{abstract}
Consortia containing a novel coccus-shaped, anaerobic heterotroph together with Pyrobaculum rods were cultivated from geothermal environments in New Zealand. Pure cultures of the cocci were only obtained from one such consortium, despite extensive attempts. Cells of this strain (AQ1.S1 $1^{\top}$ ) were regular to irregular cocci in morphology and occasionally formed large aggregates, especially when utilizing polysaccharides such as konjac glucomannan as a carbon source. Strain $\mathrm{AQ} 1 . S 1^{\top}$ is a hyperthermophile, with an optimal temperature for growth between 92 and $95^{\circ} \mathrm{C}$ (range $85-98^{\circ} \mathrm{C}$ ), and a moderate acidophile, with optimal growth occurring at $\mathrm{pH} 6 \cdot 4$ (range 5.4-7.0). Growth was inhibited by the addition of sulphur and $\mathrm{NaCl}$ (optimal growth occurred without addition of $\mathrm{NaCl}$ ) and an electron acceptor was not required. Strain $\mathrm{AQ} 1 . \mathrm{S} 1^{\top}$ utilized starch, trypticase peptone, lactose, glucose, konjac glucomannan, mannose, galactose, maltose, glycogen and $\beta$-cyclodextrin as carbon sources. The $\mathrm{G}+\mathrm{C}$ content was $52.9 \mathrm{~mol} \%$. Based on 16S rRNA gene sequence analysis and physiological features it is proposed that isolate AQ1.S1 $1^{\top}\left(=\mathrm{DSM} 17230^{\top}=\mathrm{JCM} 13409^{\top}\right)$ represents the type strain of a novel species of a new genus within the Crenarchaeota, Ignisphaera aggregans gen. nov., sp. nov.
\end{abstract}

According to $16 \mathrm{~S}$ rRNA gene analysis and phenotypic characteristics, the cultured representatives of the Crenarchaeota within the archaeal domain group into three orders, the Thermoproteales, Sulfolobales and Desulfurococcales (Burggraf et al., 1997). The Thermoproteales are rod-shaped organisms that group into the families Thermoproteaceae and Thermofilaceae, whereas members of the Sulfolobales are coccoidshaped, lobed acidophiles. The Desulfurococcales are all coccoid to disc-shaped, neutrophilic or weakly acidophilic and strict anaerobes with fermentative metabolism or anaerobic respiration, with the exception of Aeropyrum pernix and Aeropyrum camini (Sako et al., 1996; Nakagawa et al., 2004). Phenotypic and 16S rRNA gene phylogenetic analyses divide the members of the Desulfurococcales into two families, the Pyrodictiaceae and the Desulfurococcaceae. The Pyrodictiaceae forms a distinct group [genera Pyrodictium

Published online ahead of print on 23 December 2005 as DOI 10.1099/ijs.0.63899-0.

tPresent address: St Andrews University of Biomolecular Science, St Andrews, Fife KY16 9AJ, UK.

Abbreviation: DDGE, denaturing gradient gel electrophoresis.

The GenBank/EMBL/DDBJ accession numbers for the 16S rRNA gene sequences of Ignisphaera aggregans $\mathrm{AQ} 1 . \mathrm{S} 1^{\top}$ and strains Tok10A.S1, Tok37.S1 and Tok1 are DQ060321, DQ060322, D0060323 and DQ060320, respectively.
(Stetter et al., 1983), Hyperthermus (Zillig et al., 1991) and Pyrolobus (Blöchl et al., 1997)] within 16S rRNA phylogenetic trees, whereas the Desulfurococcaceae consists of a diverse range of cultured representatives (Burggraf et al., 1997). These two families can also be distinguished phenotypically by growth temperatures, where the Pyrodictiaceae consists of organisms with optimal temperatures above $100{ }^{\circ} \mathrm{C}$ and members of the Desulfurococcaceae are characterized by maximal growth temperatures of up to $100^{\circ} \mathrm{C}$. The Desulfurococcaceae consists of cocci to disc-shaped micro-organisms of the genera Desulfurococcus (Zillig et al., 1982), Aeropyrum (Sako et al., 1996; Nakagawa et al., 2004), Ignicoccus (Huber et al., 2000), Staphylothermus (Fiala et al., 1986; Arab et al., 2000), Stetteria (Jochimsen et al., 1997), Sulfophobococcus (Hensel et al., 1997), Thermodiscus (Stetter, 2003), Thermosphaera (Huber et al., 1998) and the distantly related 'Acidilobus group' consisting of Acidilobus aceticus (Prokofeva et al., 2000), Caldisphaera lagunensis (Itoh et al., 2003) and strain NC12 ('Caldococcus noboribetus'; Aoshima et al., 1996).

As part of a project investigating the microbial ecology of New Zealand's high-temperature geothermal habitats, a novel coccoid-shaped archaeum (isolate $\mathrm{AQ} 1 . S 1^{\mathrm{T}}$ ) was isolated into pure culture from co-culture with a strain of Pyrobaculum. The isolated coccus was similar in morphology and $16 \mathrm{~S}$ rRNA gene sequence to a previously identified 
archaeon, which was also in co-culture with a strain of Pyrobaculum and was obtained from a New Zealand hot spring (Götz, 1998). Other thermal habitats of New Zealand and Yellowstone National Park (WY, USA) were screened for the presence of these novel cocci by using culturing methods. In this study, we describe the novel isolate AQ1.S1 ${ }^{\mathrm{T}}$ and, based on 16S rRNA nucleotide sequence and phenotypic analysis, propose that it represents a novel genus and species, Ignisphaera aggregans gen. nov., sp. nov., within the Crenarchaeota.

Samples from hot springs and mud pools situated in the Rotorua and Tokaanu thermal areas of New Zealand were collected in sterile containers and transported back to the laboratory under ambient conditions. The medium used for enrichment and isolation contained $\left(\mathrm{g} \mathrm{l}^{-1}\right)$ : $\left(\mathrm{NH}_{4}\right)_{2} \mathrm{SO}_{4}$, $1 \cdot 3 ; \mathrm{CaCl}_{2}, 0 \cdot 074 ; \mathrm{MgSO}_{4} .7 \mathrm{H}_{2} \mathrm{O}, 0 \cdot 28 ; \mathrm{KH}_{2} \mathrm{PO}_{4}, 0 \cdot 28$; yeast extract, $0 \cdot 1$; trypticase peptone, $2 \cdot 0$; soluble starch, $2 \cdot 0$; and cystine, $0 \cdot 6$. Resazurin $(0 \cdot 1 \%, \mathrm{w} / \mathrm{v}), \mathrm{FeCl}_{3}\left(0 \cdot 28 \mathrm{~g} \mathrm{l}^{-1}\right)$ and trace elements $\left(\mathrm{mg} \mathrm{l}^{-1}: \mathrm{MnSO}_{4}, 2 \cdot 2 ; \mathrm{ZnSO}_{4} .7 \mathrm{H}_{2} \mathrm{O}, 0 \cdot 5\right.$; $\mathrm{H}_{3} \mathrm{BO}_{4}, 0 \cdot 5 ; \mathrm{CuSO}_{4}, 0 \cdot 016 ; \mathrm{Na}_{2} \mathrm{MoO}_{4} \cdot 2 \mathrm{H}_{2} \mathrm{O}, 0 \cdot 025$; and $\left.\mathrm{CoCl}_{2} \cdot 6 \mathrm{H}_{2} \mathrm{O}, 0 \cdot 046\right)$ were added at $1 \mathrm{ml} \mathrm{l}^{-1}$. The $\mathrm{pH}$ of the medium was adjusted to $7 \cdot 0$ at room temperature, and the medium was then boiled and dispensed into Hungate tubes under an $\mathrm{N}_{2}$ atmosphere, autoclaved and reduced with $10 \%$ $\mathrm{Na}_{2} \mathrm{~S} .9 \mathrm{H}_{2} \mathrm{O}$ as required. Growth was monitored using phase-contrast light microscopy. Approximately $1 \mathrm{ml}$ pool water from hot springs in Yellowstone National Park was used to inoculate media which were incubated in situ in the pool from which the inoculum originated. The media used included the enrichment medium outlined above and a modified enrichment medium, where cystine was removed and starch was replaced with konjac glucomannan (Shintoa Koeki Kaisha). The tubes were incubated in the pools for 4-7 days, after which they were transported to the laboratory under ambient conditions and microbial growth was checked using phase-contrast light microscopy.

Cells were examined under phase-contrast light microscopy. For scanning electron microscopy, cells were grown to late exponential phase, filtered through a $0 \cdot 22 \mu \mathrm{m}$ filter and fixed using $2.5 \%$ glutaraldehyde. The filter was then exposed to four changes of $0 \cdot 1 \mathrm{M}$ sodium cacodylate buffer, rinsed in water and dehydrated in increasing concentrations of ethanol (50, 75 and $90 \%$, respectively), followed by four changes of absolute ethanol. The filter was then critical point dried, sputtered with platinum and viewed using a Hitachi S-4100 field emission scanning electron microscope.

For metabolic studies, all experiments were undertaken at $90{ }^{\circ} \mathrm{C}$ unless otherwise stated and growth was documented using phase-contrast microscopy with a Thoma counting chamber (depth $0.02 \mathrm{~mm}$ ). Unless otherwise stated, carbon utilization studies involved the addition of substrates at $0 \cdot 2 \%(\mathrm{w} / \mathrm{v})$ final concentration to modified enrichment medium. The modified enrichment medium had the starch supplement omitted, reduced concentrations of yeast extract and trypticase peptone $\left(0.05\right.$ and $1.0 \mathrm{~g} \mathrm{l}^{-1}$, respectively), MOPS added to a final concentration of $25 \mathrm{mM}$ and the $\mathrm{pH}$ adjusted to approximately $7 \cdot 0$ at room temperature. A positive growth response to a substrate was only recorded when a similar cell density was achieved on three successive transfers in the same medium. For the growth response to $\mathrm{pH}$, buffers were added to the medium to a final concentration of $25 \mathrm{mM}$. The buffers used and the corresponding $\mathrm{pH}$ ranges were: MES, $\mathrm{pH} 4 \cdot 5-6 \cdot 5$; MOPS, $\mathrm{pH} 6 \cdot 5-7 \cdot 5$; Tris,

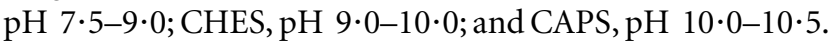
The $\mathrm{pH}$ was adjusted at a temperature of $75^{\circ} \mathrm{C}$ and the corresponding $\mathrm{pH}$ value $\left(\right.$ at $90^{\circ} \mathrm{C}$ ) was extrapolated using the appropriate $\mathrm{d}\left(\mathrm{p} K_{\mathrm{a}}\right) / \mathrm{d} t$ coefficient. Various electron acceptors were tested by replacing the cystine of the standard enrichment medium. Alternative electron acceptors were used at final concentrations of both 2.5 and $10 \mathrm{mM}$ in medium containing $25 \mathrm{mM}$ MOPS. Elemental sulphur (approx. $20 \mathrm{mg}$ ) was added to individual Hungate tubes containing $9 \mathrm{ml}$ medium prior to autoclaving. Utilization of electron acceptors was recorded as positive when the same cell density was achieved after at least two transfers in the medium. Salt tolerance was determined by adding $\mathrm{NaCl}$ directly to the standard enrichment medium. Autotrophic growth was tested in modified enrichment medium (starch omitted and both trypticase peptone and yeast extract at $\left.0.05 \mathrm{~g} \mathrm{l}^{-1}\right)$ under an $\mathrm{H}_{2} / \mathrm{CO}_{2}$ atmosphere $(80: 20$, v/v). Autotrophic medium without an electron acceptor was tested and cystine, sulphite, thiosulphate and elemental sulphur were trialled as electron acceptors.

To minimize temperature degradation in experiments to test for sensitivity to antibiotics (Peteranderl et al., 1990), antibiotics were added to cells in exponential growth $\left(90^{\circ} \mathrm{C}\right)$ to a final concentration of $100 \mu \mathrm{g} \mathrm{ml}^{-1}$.

$\mathrm{H}_{2} \mathrm{~S}$ was determined qualitatively (Huber et al., 1986). The breakdown products of growth on konjac glucomannan were tested by size exclusion chromatography through a Biogel P2 $(2 \cdot 6 \times 95 \mathrm{~cm})$ size exclusion column. Size standards of monosaccharide (glucose) and disaccharide (maltose) were run through the column at $1 \%(\mathrm{w} / \mathrm{v})$ in pure water (Milli-Q; Millipore). Growth medium containing konjac glucomannan with and without an inoculum of AQ1.S1 ${ }^{\mathrm{T}}$ cells was incubated at $90^{\circ} \mathrm{C}$. The medium was removed after approximately 3 days incubation, growth in the inoculated tubes was recorded by using light microscopy and the control tubes were confirmed as sterile. The medium was then passed through a $0.22 \mu \mathrm{m}$ filter and $10 \mathrm{ml}$ of the filtrate was snap-frozen in liquid $\mathrm{N}_{2}$ and freeze-dried. It was then resuspended in $4-5 \mathrm{ml} 100 \%$ methanol, incubated for $30 \mathrm{~min}$ in an ultrasonic cleaner and then centrifuged at $2000 \mathrm{~g}$ for $7 \mathrm{~min}$. The supernatant was transferred to a clean tube and the methanol was removed by exposure to $\mathrm{N}_{2}$ gas flow, with the tube in a $40{ }^{\circ} \mathrm{C}$ heat block. The residue was resuspended in $2 \mathrm{ml}$ Milli-Q water, sonicated for $5 \mathrm{~min}$ and passed through a $0 \cdot 22 \mu \mathrm{m}$ filter. Finally, $2 \mathrm{ml}$ was loaded onto the column for analysis. In addition, konjac glucomannan $(1 \%, \mathrm{w} / \mathrm{v})$ suspended in Milli-Q water was processed as described for the growth medium (without the $90{ }^{\circ} \mathrm{C}$ incubation) and passed through the column. 
Determination of $\mathrm{G}+\mathrm{C}$ content was undertaken in duplicate as described by Gonzalez \& Saiz-Jimenez (2002) using a Smart Cycler II (Cepheid). DNA from Escherichia coli (strain $\mathrm{DH} 5 \alpha$ ) was used as a control.

The 16S rRNA gene was amplified by PCR utilizing the primers A5F (5'-CCGTTGATCCTGCCGG-3') and U1522R (5'-AAGGAGGTGATCCARCCGCA-3'). Each PCR consisted of $1 \mu \mathrm{M}$ of each primer, $200 \mu \mathrm{M}$ dNTPs, $1 \times$ PCR buffer, $1.5 \mathrm{mM} \mathrm{MgCl} 2,1.25$ units Taq polymerase and approximately $20 \mathrm{ng}$ template DNA, in a final reaction volume of $25 \mu \mathrm{l}$. The thermocycling conditions consisted of initial denaturation at $94^{\circ} \mathrm{C}$ for $3 \mathrm{~min}$ and $30 \mathrm{~s}$, then 32 cycles of $94{ }^{\circ} \mathrm{C}$ for $30 \mathrm{~s}, 60^{\circ} \mathrm{C}$ for $30 \mathrm{~s}$ and $72^{\circ} \mathrm{C}$ for $2 \mathrm{~min}$, with a final extension at $72{ }^{\circ} \mathrm{C}$ for $6 \mathrm{~min}$. The $16 \mathrm{~S}$ rRNA gene was sequenced by using the MegaBACE DNA analysis system (Amersham Bioscience) using the primers A5F, A347F (5'-CCAGGCCCTACGGGGCGCA-3'), A915F (5' AGGAATTGGCGGGGGAGCAC-3'), A907R (5' -CCGTCAATTCCTTTGAGTTT- $\left.3^{\prime}\right)$, 519R (5'-GWATTACCGCGGCKGCTG3-'), A1335R (5'-GTGTGCAAGGAGCAGGGAC-3') and U1522R. The $16 \mathrm{~S}$ rRNA gene sequences for the coccal members of the Tok10A and Tok1 consortia were determined by using DNA extracted from a coccal-dominated culture for Tok10A.S1 and gene-cloning for Tok1 (Götz, 1998). Both strands of the $16 \mathrm{~S}$ rRNA gene were sequenced for the Tok37.S1 and AQ1.S1 ${ }^{\mathrm{T}}$ isolates, with single-strand sequencing being undertaken for Tok10A.S1 and Tok1. Sequences were checked for chimeric artefacts using the CHIMERA_CHECK online tool of the Ribosomal Database Project (Maidak et al., 2001). Phylogenetic analysis and alignment of $16 \mathrm{~S}$ rRNA gene sequences were performed using the ARB software package (Ludwig et al., 2004). The phylogenetic positions of the sequences were determined using the PHYLIP package with analysis of sequences undertaken using the programs DNADIST, DNAML, DNAPARS, FITCH, NEIGHBOR and SEQBOOT (Felsenstein, 1993).

From an in-depth study of the microbial ecology of a hot pool (designated AQ1) situated in Kuirau Park, Rotorua, New Zealand, a consortium of rod- and coccoid-shaped organisms was obtained as an enrichment from pool water incubated at $90^{\circ} \mathrm{C}$. Typically, rods dominated the cultures within the first days of incubation, with an overgrowth of cocci occurring after 4-7 days. Therefore, serial dilution $(1: 10)$ of a nascent consortium culture was undertaken to obtain a pure culture of the rod-shaped organism. A pure culture of the coccoid-shaped organism was eventually achieved after many successive dilutions (1:10) from an older consortium culture in which cocci dominated. Both cultures were maintained by weekly transfer of serial dilutions $(1: 10)$ for nearly a year prior to characterization. Sequencing of the 16S rRNA gene identified the rod as a strain of Pyrobaculum (results not shown) and the coccus (isolate AQ1.S1 ${ }^{\mathrm{T}}$ ) matched very closely (16S rRNA gene sequence and morphology) another previously identified coccus (Tok1) that had been isolated from a hot spring in Tokaanu, New Zealand (Götz, 1998). Tok1 was also enriched as a co-culture with a strain of Pyrobaculum; however, extensive attempts to obtain a pure culture of Tok1 failed (Götz, 1998). Other geothermal habitats within New Zealand and Yellowstone National Park were then screened by enrichment for the presence of these novel cocci (Table 1). Samples from New Zealand hot springs and mud pools were inoculated into anaerobic enrichment medium and incubated at $93^{\circ} \mathrm{C}$. A duplicate enrichment was incubated at $80^{\circ} \mathrm{C}$ if the in situ pool temperature was below $90^{\circ} \mathrm{C}$ (results not shown). No cocci were enriched from springs in Yellowstone National Park. However, for the New Zealand springs, as was the case for the AQ1 consortium, rod-shaped organisms were commonly observed in the medium after 2-4 days incubation, followed by an overgrowth of cocci (Table 1). Conversely, cells with a coccoid morphology dominated rod-shaped organisms in the Tok10A enrichment (coccus member designated Tok10A.S1) and an enrichment containing only cocci was obtained from pool Tok37 (coccus designated Tok37.S1). Comparison of denaturing gradient gel electrophoresis (DGGE) profiles of the enrichments and $\mathrm{AQ} 1 . S 1^{\mathrm{T}}$ suggested that all coccal-containing consortia contained AQ1.S1 ${ }^{\mathrm{T}}$-related members (results not shown). All attempts to isolate pure cultures of cocci from enrichments of pools AQ2, AQ5, Tok10A and Tok13 failed, including attempts at isolation using solid Gelrite medium (Hungate, 1969). The 16S rRNA genes of the coccal isolates from pools Tok10A and Tok37 were sequenced and were found to match closely those of AQ1.S1 ${ }^{\mathrm{T}}$ and Tok1 (results presented below). However, the Tok37 coccal enrichment also contained an atypical $16 \mathrm{~S}$ rRNA gene PCR product that contained introns, indicating that it may be a mixed culture of at least two different coccal species. Isolate $\mathrm{AQ} 1 . S 1^{\mathrm{T}}$ was therefore used for further characterization.

Cells of strain AQ1.S1 ${ }^{\mathrm{T}}$ were regular to irregular cocci, with a diameter of $1-1.5 \mu \mathrm{m}$ when grown on starch. The cells occurred singly, in pairs or as aggregates of many cells. Aggregation of cells was common when AQ1.S1 ${ }^{\mathrm{T}}$ was grown on mono-, di- or polysaccharides, as shown in Fig. 1. A weblike array of extracellular material appeared to hold cells together when cell aggregates were examined using scanning electron microscopy (Fig. 2). Attempts to stain this material using Alcian blue- and copper sulphate-based capsule/ polysaccharide staining methods were unsuccessful. Cells of Tok1 also formed aggregates, but this was not observed for either the Tok37.S1 or Tok10A.S1 cultures.

Strain AQ1.S1 ${ }^{\mathrm{T}}$ grew at $85-98^{\circ} \mathrm{C}$ and $\mathrm{pH} 5 \cdot 4-7 \cdot 0$. No growth was observed at 80 or $100{ }^{\circ} \mathrm{C}$, or at $\mathrm{pH} 4.9$ or $7 \cdot 4$. The optimum temperature and $\mathrm{pH}$ for growth on starch were between 92 and $95^{\circ} \mathrm{C}$ and $6 \cdot 4$, with a doubling time of approximately $7 \cdot 5 \mathrm{~h}$. Cultures of $\mathrm{AQ} 1 . S 1^{\mathrm{T}}$ grew to densities

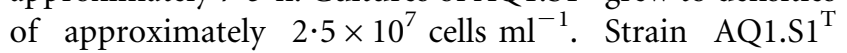
utilized starch, trypticase peptone, lactose, glucose, konjac glucomannan, mannose, galactose, maltose, glycogen and $\beta$-cyclodextrin. Weak growth was evident on beef extract and sucrose. Growth was not observed on yeast extract, cellobiose, methanol, ethanol, trehalose, pyruvate, acetate, 
Table 1. Summary of results from hot springs of New Zealand (NZ) and Yellowstone National Park (YNP)

\begin{tabular}{|c|c|c|c|c|c|}
\hline Location & Hot spring & Temp. $\left({ }^{\circ} \mathrm{C}\right)$ & pH & Enrichment & Novel cocci \\
\hline \multirow[t]{4}{*}{ NZ - Kuirau Park, Rotorua } & AQ1 & 91 & $7 \cdot 5$ & Rods and cocci & $A Q 1 . S 1^{\mathrm{T}}$ \\
\hline & AQ2 & 92 & $8 \cdot 0$ & Rods and cocci & \\
\hline & AQ3 & 87 & $7 \cdot 5$ & Rods & \\
\hline & AQ5 & 86 & $8 \cdot 0$ & Rods and cocci & \\
\hline NZ - Ohinemutu, Rotorua & $\mathrm{OH} 2$ & 94 & $9 \cdot 0$ & No growth & \\
\hline NZ - Whakarewarewa, Rotorua & WH1 & 96 & $8 \cdot 5-9 \cdot 0$ & No growth & \\
\hline \multirow[t]{5}{*}{ NZ - Tokaanu Thermal Park } & Tok3 & 85 & $6 \cdot 5$ & No growth & \\
\hline & Tok10A & 84 & $7 \cdot 0$ & Rods and cocci & Tok10A.S1 (consortium) \\
\hline & Tok13 & 97 & $6 \cdot 0$ & Rods and cocci & \\
\hline & Tok37 (mud pot) & 99 & $7 \cdot 5$ & Cocci & $\begin{array}{l}\text { Tok37.S1 (probable } \\
\text { consortia) }\end{array}$ \\
\hline & Tok13 & 90 & Neutral & Rods and cocci & Tok1 (consortium) \\
\hline \multirow[t]{3}{*}{ YNP - GOPA* } & Obsidian pool & $73 \cdot 5-76$ & $6 \cdot 0$ & $\begin{array}{l}\text { Rods and fervidobacterial } \\
\text { morphology }\end{array}$ & \\
\hline & South Obsidian pool & $75 \cdot 5-80$ & $6 \cdot 0$ & Fervidobacterial morphology & \\
\hline & $\mathrm{OH}$ & $75-85$ & $5-6$ & Rods & \\
\hline \multirow[t]{3}{*}{ YNP - Sentinel Meadows } & EM & $81-85$ & $7-8$ & No growth & \\
\hline & $\mathrm{BP}$ & $87-92 \cdot 5$ & $7-8$ & No growth & \\
\hline & Boulder spring & 86 & 8 & No growth & \\
\hline YNP - Sylvan & Sylvan spring & $75-78$ & $5-6$ & Few rods & \\
\hline \multirow[t]{2}{*}{ YNP - South Sylvan } & JTP & 89 & $6-7$ & No growth & \\
\hline & FL & 81 & 6 & Rods & \\
\hline
\end{tabular}

${ }^{\star}$ Greater Obsidian pool area.

malate, Casamino acids $(0 \cdot 1, \% \mathrm{w} / \mathrm{v})$, carboxymethylcellulose, amylopectin (corn), xanthan gum, locust gum (bean), guar gum, dextran, xylan (oat spelts, larch or birch), xylitol, xylose or amylose (corn and potato). The strain could also grow in the standard growth medium without the addition of starch. Addition of a vitamin solution (Wolin et al., 1963)

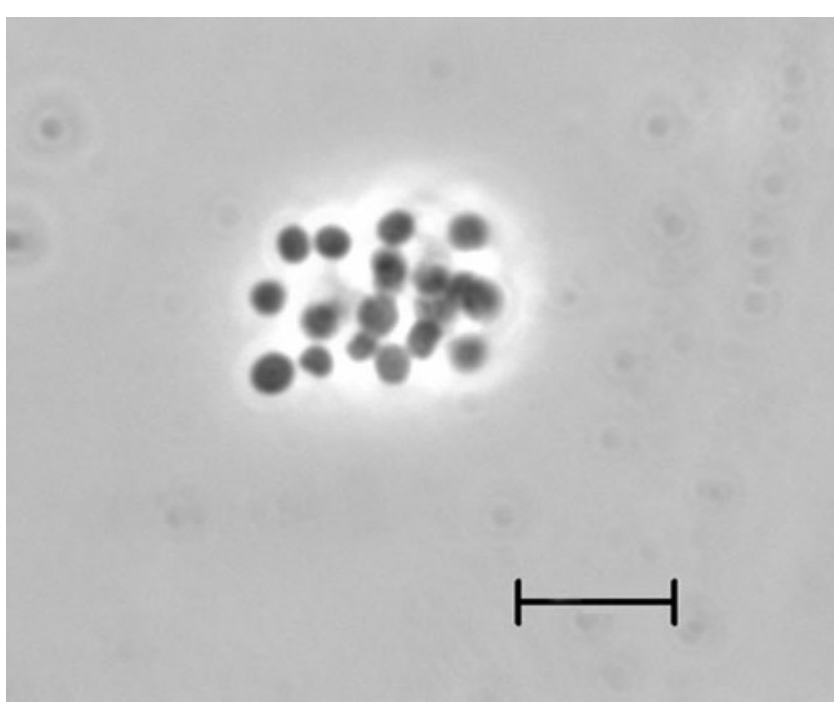

Fig. 1. Phase-contrast micrograph of an aggregation of cells of strain AQ1.S1 $1^{\top}$ grown in enrichment media. Bar, $5 \mu \mathrm{m}$. weakly promoted growth. Cultures grew in the presence of up to $0.5 \% \mathrm{NaCl}$ (optimally with no added $\mathrm{NaCl}$ ), but not at $0.75 \% \mathrm{NaCl}$. An electron acceptor was not required and the removal of cystine from the growth medium did not affect cell numbers significantly. Other electron acceptors trialled included thioglycolate, nitrate, nitrite, sulphite, thiosulphate and elemental sulphur. The electron acceptors

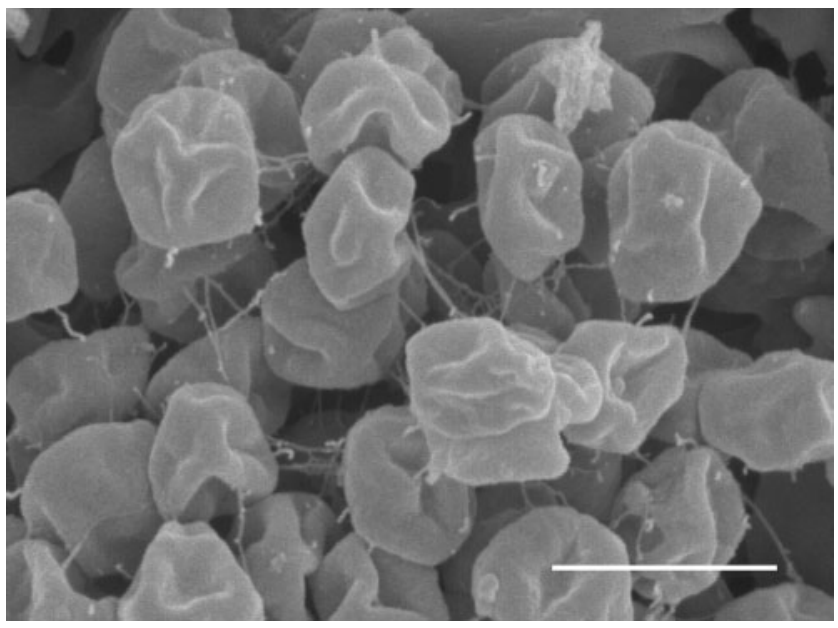

Fig. 2. Scanning electron micrograph of a dehydrated $\mathrm{AQ} 1 . S 1^{\top}$ cell aggregate grown in enrichment medium with konjac glucomannan as a carbon source. Bar, $1 \mu \mathrm{m}$. 
were inhibitory at a concentration of $10 \mathrm{mM}$ (including cystine) and at $2.5 \mathrm{mM}$ both sulphite and thioglycolate also inhibited growth of AQ1.S1 ${ }^{\mathrm{T}}$. Growth of AQ1.S1 ${ }^{\mathrm{T}}$, Tok37.S1, Tok10.S1 and Tok1 was inhibited by sulphur. No growth was detected in serum bottles under autotrophic conditions. All isolates were strict anaerobes; even trace quantities of oxygen (just sufficient to turn resazurin pink) inhibited growth. Mono- and disaccharides accumulated in $\mathrm{AQ1} 1 . \mathrm{S1}^{\mathrm{T}}$ cultures grown in medium containing konjac glucomannan, but not in sterile medium that had been exposed to the same temperature as the inoculated medium or the stock of konjac glucomannan. This most probably indicates that the konjac glucomannan is being hydrolysed enzymically by AQ1.S1 ${ }^{\mathrm{T}}$ into sugars for metabolism. Hydrogen sulphide was also detected in $\mathrm{AQ} 1 . S 1^{\mathrm{T}}$ cultures grown in enrichment medium. Cells of AQ1.S1 ${ }^{\mathrm{T}}$ were resistant to novobiocin and streptomycin but sensitive to erythromycin, chloramphenicol and rifampicin.

A near-full-length 16S rRNA gene sequence for strain $\mathrm{AQ1} 1 . \mathrm{S1}^{\mathrm{T}}$ (1491 bp) was obtained and had a $\mathrm{G}+\mathrm{C}$ ratio of $66 \%$. The 16S rRNA gene sequences of the other novel coccal isolates matched very closely that of $A Q 1 . S 1^{\mathrm{T}}$, being $99 \%$ similar to Tok37.S1 (1423 bp), $98 \%$ to Tok10A.S1 (1433 bp) and $98 \%$ to Tok1 (1191 bp), and all sequences were free of chimeric artefacts. Sequence similarities between strain AQ1.S1 ${ }^{\mathrm{T}}$ and members of the Pyrodictiaceae ranged from $91 \cdot 5$ to $94 \%$ and from 87 to $94.5 \%$ for the Desulfurococcaceae, with the closest sequence match being that with Staphylothermus marinus $\mathrm{F}^{\mathrm{T}}$ (GenBank accession no. X99560). The $\mathrm{G}+\mathrm{C}$ content of strain $\mathrm{AQ1.S1}{ }^{\mathrm{T}}$ was $52 \cdot 9 \mathrm{~mol} \%$. Phylogenetic analysis revealed that AQ1.S1 ${ }^{\mathrm{T}}$ and the other novel coccal isolates formed an independent group within the Crenarchaeota (Fig. 3). The topology of the phylogenetic tree did not change when DNADIST (FITCH and NEIGHBOR), DNAML or DNAPARS analysis was used, or when the shorter 16S rRNA gene sequence of Tok1 (1195 bp) was removed. Likewise, the structure of the phylogenetic tree did not change with the inclusion of Methanopyrus kandleri DSM $6324^{\mathrm{T}}$ (GenBank accession no. M59932), Archaeoglobus fulgidus DSM $4304^{\mathrm{T}}$ (Y00275) and Methanocaldococcus jannaschii DSM $2661^{\mathrm{T}}$ (M59126) as additional outgroups.

These novel coccoid micro-organisms are widely distributed in high-temperature, near-neutral hot pools and mud pools in New Zealand. An unusual feature was that the $\mathrm{pH}$ range for growth for the type strain $\mathrm{AQ} 1 . S 1^{\mathrm{T}}$ determined in laboratory culture was between $\mathrm{pH} 5 \cdot 4$ and $7 \cdot 0$ (at $90^{\circ} \mathrm{C}$ ), yet isolation was regularly achieved from more alkaline springs. This was not the result of an aberrant $\mathrm{pH}$ reading, as the $\mathrm{pH}$ of the AQ1 pool was measured at regular intervals over at least a year and was consistently above $\mathrm{pH} 7 \cdot 0$ (range measured was $7 \cdot 4-8 \cdot 2$ ). Moreover, we failed to isolate or detect molecular signatures of $\mathrm{AQ} 1 . \mathrm{S1}^{\mathrm{T}}$-related organisms by DGGE analysis in pools where the $\mathrm{pH}$ was below $\mathrm{pH} 6 \cdot 7$ yet, ostensibly, the organism should be able to proliferate under such conditions. These novel coccus-shaped organisms

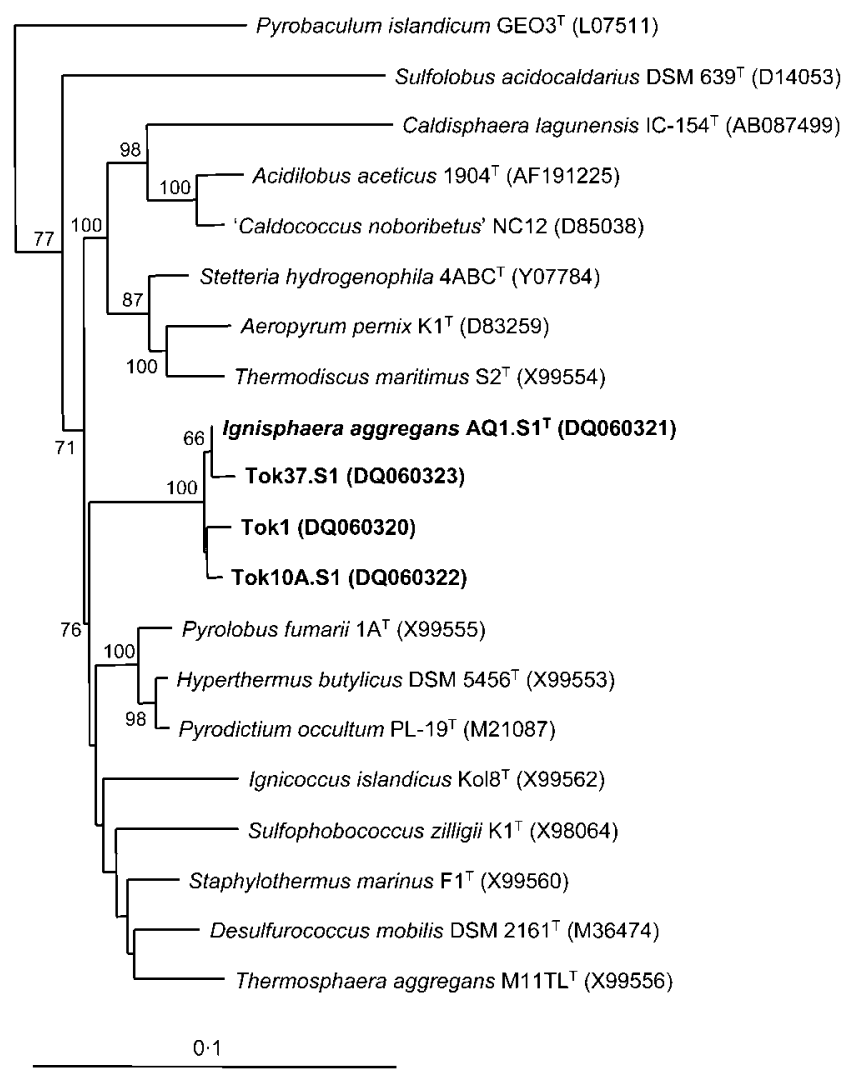

Fig. 3. Phylogenetic tree based on analysis of the $16 \mathrm{~S}$ rRNA gene sequences of strain $\mathrm{AQ} 1 . S 1^{\top}$, the other novel isolates Tok37.S1, Tok10A.S1 and Tok1 and representative species of the Crenarchaeota, showing the positions of the novel cocci. The dendrogram was produced with DNADIST (neighbour-joining) analysis using $1027 \mathrm{bp}$ of aligned sequence. The tree was rooted with Thermococcus celer DSM $2476^{\top}$ (GenBank accession no. M21529; not shown). Bootstrap values $>65 \%$ are shown from 100 replicates. Bar, $10 \%$ sequence divergence.

were not enriched from pools with similar characteristics in Yellowstone National Park. Moreover, the use of 'Ignisphaera-specific' enrichment media, i.e. no electron acceptor and konjac glucomannan as a carbon source, did not yield consortia containing coccoid organisms.

Commonly, the novel coccus-shaped organisms grew commensally with species of Pyrobaculum, with the exception of Tok37.S1, and, although the Pyrobaculum sp. could readily be obtained as a pure culture, this proved impossible with the coccus-shaped organisms (with the exception of $\mathrm{AQ1} 1 . \mathrm{S1}^{\mathrm{T}}$ ) and may be indicative of a metabolic dependency of the cocci with Pyrobaculum. In fact, the outgrowth of cocci following the development of rods (Pyrobaculum sp.) within cultures may be due to the cocci utilizing a product excreted by the rod-shaped members of the consortium. Likewise, the presence of a second atypical 16S rRNA gene PCR product for Tok37.S1 may indicate another coccal member that Tok37.S1 might be dependent upon. 
$\mathrm{AQ1} . S 1^{\mathrm{T}}$ is a coccoid-shaped, anaerobic, moderately acidophilic, heterotrophic hyperthermophile, with maximum growth occurring below $100^{\circ} \mathrm{C}$. These morphological and phenotypic attributes fit within the description of the family Desulfurococcaceae (Burggraf et al., 1997). The ability of strain $\mathrm{AQ} 1 . S 1^{\mathrm{T}}$ to grow in media with no exogenous electron acceptor indicates its capacity to ferment polysaccharides and complex proteinaceous substrates. The fermentation of polysaccharides and/or peptides has also been noted for other members of the family Desulfurococcaceae, such as Desulfurococcus (Zillig et al., 1982), Thermosphaera (Huber et al., 1998), Staphylothermus (Fiala et al., 1986), Sulfophobococcus (Hensel et al., 1997) and both Acidilobus (Prokofeva et al., 2000) and Caldisphaera (Itoh et al., 2003) of the 'Acidilobus group'. The formation of cell aggregates that was typical of AQ1.S1 ${ }^{\mathrm{T}}$ and Tok1 has also been noted in cultures of members of the Desulfurococcaceae, for example, cells of Caldisphaera lagunensis clump together (Itoh et al., 2003) and Thermosphaera aggregans (Huber et al., 1998), Staphylothermus marinus and Staphylothermus hellenicus grow as grape-like aggregates (Fiala et al., 1986; Arab et al., 2000). However, the growth inhibition by sulphur of the novel cocci does not accord with the description of the Desulfurococcaceae, as its members typically use elemental sulphur for reduction or respiration (Burggraf et al., 1997). However, Aeropyrum camini (Nakagawa et al., 2004), Thermosphaera aggregans (Huber et al., 1998) and Sulfophobococcus zilligii (Hensel et al., 1997) are already exceptions within the Desulfurococcaceae in this regard.

By themselves, the phenotypic characteristics of the novel cocci suggest that they represent members of the Desulfurococcaceae; however, based on 16S rRNA gene analysis the novel coccal isolates form an independent lineage within the Crenarchaeota with a $100 \%$ bootstrap value and do not group within any other lineage within the Desulfurococcaceae. Consequently, the 'Ignisphaera group' constitutes a novel deep-branching genus of the Desulfurococcaceae, branching independently from both the families Desulfurococcaceae and Pyrodictiaceae. Therefore, inclusion of the 'Ignisphaera group' and the proposal of strain AQ1.S1 ${ }^{\mathrm{T}}$ as representing a new genus and species within the Desulfurococcales may be controversial, as is the case for the 'Acidilobus group', because of its independent grouping based on 16S rRNA gene analysis and acidophilic growth optima (Itoh et al., 2003). Despite the above considerations, with regard to the phylogenetic placement of strain $\mathrm{AQ1} . \mathrm{S1}^{\mathrm{T}}$ and related isolates, we propose a new genus within the Desulfurococcales as the most conservative origin for this lineage. However, as more representatives of the Crenarchaeota are cultured and characterized the position of the 'Ignisphaera-type' isolates may be resolved.

\section{Description of Ignisphaera gen. nov.}

Ignisphaera (Ig.ni.sphae' ra. L. n. ignis fire, L. fem. n. sphaera ball, N.L. fem n. Ignisphaera fire ball).
Cells are regular to irregular cocci that occur singly, in pairs or as aggregates. Hyperthermophilic anaerobe. Moderate acidophile. Heterotrophic. Electron acceptor is not absolutely necessary. Elemental sulphur and $\mathrm{NaCl}$ inhibit growth. The 16S rRNA gene groups within the Crenarchaeota. Habitat is terrestrial, near-neutral hot springs and mud pots. The type species is Ignisphaera aggregans.

\section{Description of Ignisphaera aggregans sp. nov.}

Ignisphaera aggregans (ag'gre.gans. L. part. adj. aggregans aggregate forming, aggregating clumping).

Cells are approximately $1-1.5 \mu \mathrm{m}$ in size when grown on starch. Temperature and $\mathrm{pH}$ ranges for growth are $85-98{ }^{\circ} \mathrm{C}$ (optimum at $92-95^{\circ} \mathrm{C}$ ) and $\mathrm{pH} 5 \cdot 4-7 \cdot 0$ (optimum pH 6.4). Obligate anaerobe. Ferments both poly- and disaccharides. Grows at low salinity $(<0.5 \% \mathrm{NaCl})$ and optimally without addition of $\mathrm{NaCl}$. Resistant to novobiocin and streptomycin but sensitive to erythromycin, chloramphenicol and rifampicin. The $\mathrm{G}+\mathrm{C}$ content of the DNA is $52.9 \mathrm{~mol} \%$.

The type strain is Ignisphaera aggregans AQ1.S1 ${ }^{\mathrm{T}}$ ( = DSM $17230^{\mathrm{T}}=\mathrm{JCM} 13409^{\mathrm{T}}$ ), which was isolated from a nearneutral, boiling spring in Kuirau Park, Rotorua, New Zealand.

\section{Acknowledgements}

We would like to thank Dr Melanie Holland and Professor Everett Shock for the invitation to sample springs in Yellowstone National Park.

\section{References}

Aoshima, M., Nishibe, Y., Hasegawa, M., Yamagishi, A. \& Oshima, T. (1996). Cloning and sequencing of a gene encoding $16 \mathrm{~S}$ ribosomal RNA from a novel hyperthermophilic archaebacterium NC12. Gene 180, $183-187$.

Arab, H., Völker, H. \& Thomm, M. (2000). Thermococcus aegaeicus sp. nov. and Staphylothermus hellenicus sp. nov., two novel hyperthermophilic archaea isolated from geothermally heated vents off Palaeochori Bay, Milos, Greece. Int J Syst Evol Microbiol 50, 2101-2108.

Blöchl, E., Rachel, R., Burggraf, S., Hafenbradl, D., Jannasch, H. W. \& Stetter, K. O. (1997). Pyrolobus fumarii, gen. and sp. nov., represents a novel group of archaea, extending the upper temperature limit for life to $113^{\circ} \mathrm{C}$. Extremophiles 1, 14-21.

Burggraf, S., Huber, H. \& Stetter, K. O. (1997). Reclassification of the crenarchaeal orders and families in accordance with $16 \mathrm{~S}$ rRNA sequence data. Int J Syst Bacteriol 47, 657-660.

Felsenstein, J. (1993). PHYLIP (phylogeny inference package), version 3.5c. Distributed by the author. Department of Genome Sciences, University of Washington, Seattle, USA.

Fiala, G., Stetter, K. O., Jannasch, H. W., Langworthy, T. A. \& Madon, J. (1986). Staphylothermus marinus sp. nov. represents a novel genus of extremely thermophilic submarine heterotrophic Archaebacteria growing up to $98^{\circ} \mathrm{C}$. Syst Appl Microbiol 8, 106-113.

Gonzalez, J. M. \& Saiz-Jimenez, C. (2002). A fluorimetric method for the estimation of $\mathrm{G}+\mathrm{C}$ mol\% content in microorganisms by thermal denaturation temperature. Environ Microbiol 4, 770-773. 
Götz, D. K. (1998). The characterisation of three hyperthermophilic archaea from New Zealand hot springs. PhD thesis, University of Waikato, Hamilton, New Zealand.

Hensel, R., Matussek, K., Michalke, K., Tacke, L., Tindall, B. J., Kohlhoff, M., Siebers, B. \& Dielenschneider, J. (1997). Sulfophobococcus zilligii gen. nov. spec. nov. a novel hyperthermophilic archaeum isolated from hot alkaline springs of Iceland. Syst Appl Microbiol 20, 102-110.

Huber, R., Langworthy, T. A., König, H., Thomm, M., Woese, C. R., Sleytr, U. B. \& Stetter, K. O. (1986). Thermotoga maritima sp. nov. represents a new genus of unique extremely thermophilic eubacteria growing up to $90^{\circ} \mathrm{C}$. Arch Microbiol 144, 324-333.

Huber, R., Dyba, D., Huber, H., Burggraf, S. \& Rachel, R. (1998). Sulfur-inhibited Thermosphaera aggregans sp. nov., a new genus of hyperthermophilic archaea isolated after its prediction from environmentally derived $16 \mathrm{~S}$ rRNA sequences. Int J Syst Bacteriol 48, 31-38.

Huber, H., Burggraf, S., Mayer, T., Wyschkony, I., Rachel, R. \& Stetter, K. O. (2000). Ignicoccus gen. nov., a novel genus of hyperthermophilic, chemolithoautotrophic Archaea, represented by two new species, Ignicoccus islandicus sp. nov. and Ignicoccus pacificus sp. nov. Int J Syst Evol Microbiol 50, 2093-2100.

Hungate, R. E. (1969). A roll-tube method for the cultivation of strict anaerobes. Methods Microbiol 3B, 117-132.

Itoh, T., Suzuki, K., Sanchez, P. C. \& Nakase, T. (2003). Caldisphaera lagunensis gen. nov., sp. nov., a novel thermoacidophilic crenarchaeote isolated from a hot spring at Mt Maquiling, Philippines. Int J Syst Evol Microbiol 53, 1149-1154.

Jochimsen, B., Peinemann-Simon, S., Völker, H., Stüben, D., Botz, R., Stoffers, P., Dando, P. R. \& Thomm, M. (1997). Stetteria hydrogenophila, gen. nov. and sp. nov., a novel mixotrophic sulfur-dependent crenarchaeote isolated from Milos, Greece. Extremophiles 1, 67-73.

Ludwig, W., Strunk, O., Westram, R. \& 29 other authors (2004). ARB: a software environment for sequence data. Nucleic Acids Res 32, 1363-1371.

Maidak, B. L., Cole, J. R., Lilburn, T. G. \& 7 other authors (2001). The RDP-II (Ribosomal Database Project). Nucleic Acids Res 29, 173-174.
Nakagawa, S., Takai, K., Horikoshi, K. \& Sako, Y. (2004). Aeropyrum camini sp. nov., a strictly aerobic, hyperthermophilic archaeon from a deep-sea hydrothermal vent chimney. Int J Syst Evol Microbiol 54, 329-335.

Peteranderl, R., Shotts, E. B., Jr \& Wiegel, J. (1990). Stability of antibiotics under growth conditions for thermophilic anaerobes. Appl Environ Microbiol 56, 1981-1983.

Prokofeva, M. I., Miroshnichenko, M. L., Kostrikina, N. A., Chernyh, N. A., Kuznetsov, B. B., Tourova, T. P. \& Bonch-Osmolovskaya, E. A. (2000). Acidilobus aceticus gen. nov., sp. nov., a novel anaerobic thermoacidophilic archaeon from continental hot vents in Kamchatka. Int J Syst Evol Microbiol 50, 2001-2008.

Sako, Y., Nomura, N., Uchida, A., Ishida, Y., Morii, H., Koga, Y., Hoaki, T. \& Maruyama, T. (1996). Aeropyrum pernix gen. nov., sp. nov., a novel aerobic hyperthermophilic archaeon growing at temperatures up to $100^{\circ} \mathrm{C}$. Int J Syst Bacteriol 46, 1070-1077.

Stetter, K. O. (2003). Thermodiscus maritimus gen. nov., sp. nov. In Validation of Publication of New Names and New Combinations Previously Effectively Published Outside the IJSEM, List no. 89. Int J Syst Evol Microbiol 53, 1-2.

Stetter, K. O., König, H. \& Stackebrandt, E. (1983). Pyrodictium gen. nov., a new genus of submarine disc-shaped sulphur reducing archaebacteria growing optimally at $105^{\circ}$ C. Syst Appl Microbiol 4, 535-551.

Wolin, E. A., Wolin, M. J. \& Wolfe, R. S. (1963). Formation of methane by bacterial extracts. J Biol Chem 238, 2882-2886.

Zillig, W., Stetter, K. O., Prangishvilli, D., Schäfer, W., Wunderl, S., Janekovic, D., Holz, I. \& Palm, P. (1982). Desulfurococcaceae, the second family of the extremely thermophilic, anaerobic, sulfurrespiring Thermoproteales. Zentralbl Bakteriol Mikrobiol Hyg I Abt Orig C 3, 304-317.

Zillig, W., Holz, I. \& Wunderl, S. (1991). Hyperthermus butylicus gen. nov., sp. nov., a hyperthermophilic, anaerobic, peptide-fermenting, facultatively $\mathrm{H}_{2} \mathrm{~S}$-generating archaebacterium. Int J Syst Bacteriol 41, 169-170. 